Editorial

\title{
Reactionary Politics and Resentful Affect in Populist Times
}

\author{
Tereza Capelos ${ }^{1, *}$, Stavroula Chrona ${ }^{2}$, Mikko Salmela ${ }^{3,4}$ and Cristiano Bee ${ }^{5}$ \\ ${ }^{1}$ Department of Political Science and International Studies, University of Birmingham, UK; E-Mail: t.capelos@bham.ac.uk \\ 2 Department of European and International Studies, King's College London, UK; E-Mail: stavroula.chrona@kcl.ac.uk \\ ${ }^{3}$ Faculty of Social Sciences, University of Helsinki, Finland; E-Mail: mikko.salmela@helsinki.fi \\ ${ }^{4}$ Center for Subjectivity Research, Department of Communication, University of Copenhagen, Denmark \\ ${ }^{5}$ School of Social Sciences, Oxford Brookes University, UK; E-Mail: cbee@brookes.ac.uk \\ * Corresponding author
}

Submitted: 22 July 2021 | Published: 27 August 2021

\begin{abstract}
This thematic issue brings together ten articles from political psychology, political sociology, philosophy, history, public policy, media studies, and electoral studies, which examine reactionary politics and resentful affect in populist times.
\end{abstract}

\section{Keywords}

affect; emotions; populism; radicalism; reactionism; resentment

\section{Issue}

This editorial is part of the issue "Reactionary Politics and Resentful Affect in Populist Times" edited by Tereza Capelos (University of Birmingham, UK), Stavroula Chrona (King's College London, UK), Mikko Salmela (University of Helsinki, Finland / University of Copenhagen, Denmark), and Cristiano Bee (Oxford Brookes University, UK).

(C) 2021 by the authors; licensee Cogitatio (Lisbon, Portugal). This editorial is licensed under a Creative Commons Attribution 4.0 International License (CC BY).

This thematic issue examines reactionary politics and resentful affect in populist times. It brings together ten articles on research agendas from political psychology, political sociology, philosophy, history, public policy, media studies, and electoral studies, which discuss extensively a particular set of interrelated puzzles of grievance politics: the distrust and disillusionment expressed towards institutions of democracy, the reluctance or diminished capacity to engage with facts, the increase in the prevalence of anti-immigration, anti-science and anti-elite sentiments, the rise in spiteful and intolerant antagonisms. These orientations and affects towards governments and politics coincide with the rise of populist parties around the globe, and the strengthened traction of nationalist, authoritarian, and extremist discourses in mainstream and fringe political actors and movements. There can be no doubt that these conditions generate significant agitations with profound political, social, psychological, and cultural consequences, which urgently need solutions.

We focus on "reactionism" as a lasting and insistent cluster orientation that consolidates cognitive, affec- tive and motivational drivers of populist support. It has become apparent to us through our own research that at the core of conflicts and challenges for democratic politics lie contrasting and incompatible ways of making sense of the world, which in turn rest on a divide involving attitudes towards change (Wolfe, 1923). Reactionism, like radicalism seeks to urgently uproot the status quo. It is distinguished from conservatism which seeks to preserve the status quo, or progressivism and retrogressivism which harbour the desire for gradual and orderly reform (Capelos \& Katsanidou, 2018). Uncompromising reactionism and revolutionary radicalism share disaffection with the present but their realities collide as they gaze in opposite directions: the reactionary orientation towards the restoration of an often idealised past, and the radical orientation towards the establishment of a different, imagined future. These orientations, often in interaction with each other, are candidates for anomic and violent political engagement founded on grievances, disaffection and anti-social stances towards others in society.

We focus on "resentful affect" in order to understand the frustrated, vengeful and bitter emotions of 
populist politics, which in our view extend beyond binary analyses of political emotionality of angry vs. afraid citizens (Capelos et al., 2017). Our research on the political affectivity of reactionary grievance politics finds it to be frustrated and aggressive, anxious and spiteful, sour and bitter, perpetuating vindictiveness and selfvictimization (Bee \& Chrona, 2017; Capelos \& Chrona, 2018; Capelos \& Demertzis, 2018). These seemingly contradictory affective experiences we identify here as "resentful affect" contain resentment expressed as moral anger at unfairness or injustice, as well as the underexplored psychological experience of ressentiment (written in italics throughout this thematic issue and the field more broadly, to denote the technical term introduced by Nietzsche [1885/1961] and elaborated by Scheler [1915/1961]). Ressentiment is marked by the unconscious transformation of envy, shame, or inefficacious anger of powerless and frustrated individuals into vindictiveness and hatred, compensating for a chronic perceived inferiority and deficiency to attain what one values or desires. The "individual of ressentiment" alters the value of what is desired to undesirable, and the value of the self from inferior to a morally superior victim. Its conviction of moral victimhood is preserved through socialsharing practices with like-minded peers with long-term anti-social implications. Ressentiment can be manifested in animus politics as its outcome emotions of hatred, vindictiveness and resentment, and also scapegoating, vengeance, and intolerance (Capelos \& Demertzis, 2018; Salmela, 2019; Salmela \& von Scheve, 2017, 2018).

The original articles hosted here investigate further the conceptual and empirical puzzles arising from reactionary and resentful politics. They offer in-depth understanding of the individual and collective dynamics of resentful reaction, focusing on the convictions, sympathies, loyalties, and beliefs that feed it, the ressentimentful emotional mechanism that delivers it, the values that motivate it, and the emotions it stirs up. They investigate the role of personality and group attachments in explaining reactionary anti-stances. They shed light on reciprocal processes of reactionary radicalization and resentful affectivity. They trace social media campaigns in framing issues that resonate with citizens' worries and frustrations; they analyse the function of symbols in giving meaning, purpose, and passion to group identities. They highlight the importance of economic hardship and cultural and political contexts in generating or appeasing grievances. And together they interrogate the social, political, and psychological function of resentful reaction for democratic politics, tackling theoretical and empirical questions that are as challenging as they are important.

The thematic issue begins with the article by Mikko Salmela and Tereza Capelos (2021) titled "Ressentiment: A Complex Emotion or an Emotional Mechanism of Psychic Defenses?" An analytical philosopher (Salmela) and a political psychologist (Capelos) recognize ressentiment as the affective driver of reactionism, Islamic fundamentalism, and radicalism and join forces to tackle the puzzle many scholars have grappled with: what is ressentiment. They examine theoretical accounts from philosophy, sociology, psychoanalysis, and political psychology, and break new ground theorising ressentiment as an emotional mechanism triggered by envy, shame, or inefficacious anger, which produces resentment, indignation, and hatred through a four-stage process that involves idiosyncratic defences determined by individuals' ego strength. Their theoretical model specifically explores individual and social level processes. Intraindividually, the emotional mechanism of ressentiment reinforces a morally superior sense of victimhood and expedites two parallel transvaluation processes which change what was once desired to undesirable and rotten, and one's inferior self to being a morally superior victim. Social sharing with like-minded peers consolidates the other-directed negative emotions, values, and identities in ressentiment through shallow twinship bonds giving rise to destructive and vengeful collective behaviours.

In "Islamist and Nativist Reactionary Radicalization in Europe," Ayhan Kaya (2021) makes a strong contribution to understanding co-radicalization by emphasising the defensive and reactionary response of Islamist youth and right-wing nativist-populist Europe youth, suffering from social, economic, and political forms of exclusion, subordination, alienation, humiliation, and isolation. Kaya adopts an interdisciplinary perspective joining insights from politics, anthropology, psychology, and geography to extend our understanding of co-radicalization through interviews of young people in Belgium, France, Germany, and the Netherlands. He finds the drivers of radicalization between the two groups to be similar, highlighting deprivations that span across political, socioeconomic, and psychological conditions. In this project funded by the European Research Council (ERC), Kaya explains that reactionary Islamist and right-wing populistnativist groups are best understood as defensive movements of individuals pressurised by modernization and globalization. Their co-radicalization is in essence a product of the identity politics of neoliberalism giving rise to Islamophobia, nativism, and religio-political and ethnocultural polarizations.

In "Reimagining the Medieval: The Utility of Ethnonational Symbols for Reactionary Transnational Social Movements" Matthew Godwin and Elisabeth Trischler (2021) bring the perspective of historical analysis to the examination of ethnonational symbols as strategic framing devices used by reactionary movements in Europe. Focusing on the Identitarians and the Defence Leagues, Godwin and Trischler analyse images and narratives that feature knights and the crusades and show how "radical nostalgia" of the medieval period sits at the core of their reimagination of a lost "golden age" of a Christian Europe. Their research highlights the value of ethnonational symbols derived from the medieval period for identity construction and identity promotion. This reactionary "political medievalism" is urgent, nativist, 
and xenophobic. It is constructed on a "us against them" struggle, mobilizes against "threats" by assigning blame, and legitimizes the use of violence against multiculturalism and Islam. The moralization of the objective of these reactionary movements invites research on their ressentimentful affective character.

In "Double Ressentiment: The Political Communication of Kulturkampf in Hungary," Balázs Kiss (2021) employs qualitative content analysis to examine ressentiment as an affective style that dominates the social media discourses of the culture war between opposing political camps in Hungary. The affective style of ressentiment refers to the inclination to interpret events as a recurrent unjust and inevitable injury from the position of the helpless victim. As the identity of the victim is redefined to a moral martyr through the emotional mechanism of ressentiment, comparison with others who seem "better-off" feeds envy and incubates aversions. Without doubt, the value of this article extends beyond understanding Orbanism and Hungarian politics: It offers political communication insights on the way emotions, and in particular ressentimentful impotent vengeance, hatred, fear, and powerlessness, can be employed by opposing actors to manage citizens' responses to politics. Transvaluation, scapegoating, blame externalization, and vindictive moral superiority define the two-way interactions between opposing political communities that Kiss aptly calls "double-ressentiment."

Karen Celis, Louise Knops, Virginie Van Ingelgom, and Soetkin Verhaegen (2021) examine the implications of expressing resentment for the "crisis of representative democracy," in their article titled "Resentment and coping with the democratic dilemma." Using data from four focus groups conducted in Belgium with members of the Yellow Vests and Youth for Climate movements, as well as individuals from socially disadvantaged positions, the authors identify strong feelings of anger, fear, disappointment, and unfairness, but also feelings of empowerment, enthusiasm, and hope in discussions involving representative democracy. The objects of this resentful affectivity varied as citizens directed their anger, disappointment, perceptions of unfairness, and hope in different ways when they discussed elections, politicians, policy implementation, and the democratic system overall. Celis and her colleagues listen very competently to the "heart" of representative democracy and identify its complex affective profile. The "democratic dilemma" highlighted by the authors involves recognizing frustrations and grievances while maintaining hope and sustaining democratic values and ideals. The authors do not rush to easy answers, recognizing the complexity of their puzzle. They suggest future studies could explore further shifts "within resentful affectivity," to gain understanding on the distinctions between resentment and ressentiment as some citizens remain within, and others go beyond democratic boundaries in their political engagement.

Sabrina Jasmin Mayer and Christoph Giang Nguyen (2021) examine the mechanism that connects reac- tionary political orientations, personality predisposition to narcissistic rivalry, anger, and support for radical right populist parties (RRP) in their contribution titled "Angry Reactionary Narcissists? Anger Activates the Link Between Narcissism and Right-Populist Party Support." They hypothesise that narcissistic rivalry, a maladaptive path of grandiose narcissism, motivates voting for the RRP party Alternative für Deutschland and that this effect is mediated by reactionary political orientations and activated by anger. They test this hypothesis through mediation analysis of GESIS panel data from Germany. The authors find that indicators of reactionary political orientations predict RRP support. Moreover, high levels of generalized anger are needed to activate the relationship between narcissistic rivalry, reactionary values, and RRP support. These findings raise interesting questions about the role of anger and might explain why only some people show support for RRP. As the authors note, the relationship between narcissistic rivalry, reactionary orientations, and political preferences begs for further investigation.

Gavin Brent Sullivan (2021) introduces the framework of affective practice in his analysis of political reactionism in England. In his article "Political Reactionism as Affective Practice: UKIP Supporters and Non-Voters in Pre-Brexit England" the author examines how the ressentimentful affective features of reactionary political stances are created, shared or suppressed, facilitated, mobilised, and transformed in everyday actions. Using reflexive thematic analysis of interview data with UKIP voters and non-voters, Sullivan finds evidence of ressentiment (shame, transvaluation, victimhood, a sense of loss, powerlessness) and reactionism (desire for change backwards, nostalgia, opposition to the status quo). He also notes that expressions of anger were used to conceal shame or proneness to humiliation during discussions of anti-political stances. Sullivan's study urges us to pay attention to emotions used in conversation that cover painful feelings, and invites us to engage more with rich data collection methodologies that examine emotional activity and practices on the left and the right of the ideological spectrum.

Diogo Ferrari (2021) tackles the question of why populist parties find support for their ideas among the electorate, in his article "Perceptions, Resentment, Economic Distress, and Support for Right-Wing Populist Parties in Europe." Ferrari focuses on micro-level effects of household-level economic conditions, and notes that low and middle-income populations are more vulnerable to economic distress. This in turn increases their resentment (measured here as dissatisfaction with democracy), and their threat assessment of immigration, which then increases the likelihood of voting for populist parties. Using European Social Survey (ESS) data across 18 countries, Ferrari shows that voting for right-wing populist parties is predicted by changes in household income, while accounting for the mediation effect of an index measuring economic and cultural threat and 
satisfaction with democracy. This article draws attention to the micro-level hardships that can attract voters to solutions offered by right wing populists, adding to literature that favours macro level economic or cultural explanations. Improving families' finances and alleviating economic hardships, shows Ferrari, could be an effective measure to curb the rise of populism.

In "Feeling Left Behind by Political Decisionmakers: Anti-Establishment Sentiment in Contemporary Democracies," Luigi Droste (2021) deals with the pressing puzzle of what drives populist and reactionary discontent in democratic societies. Using survey data from 20 contemporary democracies from two International Social Survey Program (ISSP) waves, Droste uses a multilevel hybrid model that allows for individual and country level effects and longitudinal components. Droste finds differences between counties and individuals: Anti-establishment attitudes are more widespread among publics in countries exposed to higher levels of public corruption and increasing levels of income inequality, and also among citizens that are younger and in lower ranks of society. Moreover, citizens who experience discontent show increased support for anti-elite parties and make use of online options to express their opinions. Recognizing the lack of affect measures in cross-country comparative datasets, Droste concludes with an important question: Is the political action of those "feeling left behind" resentful or ressentimentful in its core?

Maximilian Conrad (2021) focuses on "Post-Truth Politics, Digital Media and the Politicization of the Global Compact for Migration." Acknowledging the important role of social media as vehicles of disinformation, Conrad investigates the debate over the Global Compact for Safe, Orderly and Regular Migration (GCM) in Germany, Austria, and Sweden. Using process-tracing, the author analyses the frames used by right-wing populist actors, how they were received by the public, and describes the ways in which they generated communicative power against the GCM, making it a salient issue across national public spheres and political institutions. The study showcases the crucial role of digital and social media for the politicization of issues capitalised upon by right-wing populist actors for political gain. It closes with the invitation to engage seriously with the complexities and impacts of digital engagement that generate resentment and fear and challenge deliberative democracy in post-truth politics.

If animus and caritas are the two sides of our human condition, reconciling them can be our perennial struggle for democratic politics. The above articles forward new theory, survey the field, complement each other by employing qualitative and quantitative methodologies, and collectively deliver research that seeks to make constructive contributions to this pressing puzzle: If the reactionary orientation obstructs innovation in favour of renovation and harbours bitter and vengeful affects, can its needs be reconciled within the framework of democratic politics that seeks growth and development, and what are the avenues for positive, constructive engagement with reactionary minds and hearts? We feel privileged to work with our colleagues on investigating this puzzle and to deliver this thematic issue. We recognize there is still a long way to go and hope this thematic issue offers valuable knowledge, new insights, and opportunities for further interdisciplinary research and collaborative work.

\section{Acknowledgments}

We thank the contributing authors for their dedication and hard work, the Politics and Governance editorial board for their enduring support and professionalism, and the anonymous reviewers for their generous reviews and valuable input. This thematic issue and its articles are stronger because of their constructive feedback.

\section{Conflict of Interests}

The authors declare no conflict of interests.

\section{References}

Bee, C., \& Chrona, S. (2017). Youth activists and occupygezi: Patterns of social change in civic and political activism in Turkey. Turkish Studies, 18(1), 157-181.

Capelos, T., \& Chrona, S. (2018). The map to the heart: An analysis of political affectivity in Turkey. Politics and Governance, 6(4), 144-158.

Capelos, T., \& Katsanidou, A. (2018). Reactionary politics: Explaining the psychological roots of anti preferences in European integration and immigration debates. Political Psychology, 39(6), 1271-1288.

Capelos, T., \& Demertzis, N. (2018). Political action and resentful affectivity in critical times. Humanity \& Society, 42(4), 410-433. https://doi.org/10.1177/ 0160597618802517

Capelos, T., Katsanidou, A., \& Demertzis, N. (2017). Back to black: Values, ideologies, and the black box of political radicalization. Science and Society, 35, 35-68.

Celis, K., Knops, L., Van Ingelgom, V., \& Verhaegen, S. (2021). Resentment and coping with the democratic dilemma. Politics and Governance, 9(3), 237-247.

Conrad, M. (2021). Post-truth politics, digital media, and the politicization of the global compact for migration. Politics and Governance, 9(3), 301-311.

Droste, L. (2021). Feeling left behind by political decisionmakers: Anti-establishment sentiment in contemporary democracies. Politics and Governance, 9(3), 288-300.

Ferrari, D. (2021). Perceptions, resentment, economic distress, and support for right-wing populist parties in Europe. Politics and Governance, 9(3), 274-287.

Godwin, M., \& Trischler, E. (2021). Reimagining the medieval: The utility of ethnonational symbols for reactionary transnational social movements. Politics and Governance, 9(3), 215-226.

Kaya, A. (2021). Islamist and nativist reactionary radi- 
calisation in Europe. Politics and Governance, 9(3), 204-214.

Kiss, B. (2021). Double ressentiment. The political communication of Kulturkampf in Hungary. Politics and Governance, 9(3), 227-236.

Mayer, S. J., \& Nguyen, C. G. (2021). Angry reactionary narcissists? Anger activates the link between narcissism and right-populist party support. Politics and Governance, 9(3), 248-259.

Nietzsche, F. (1961). Genealogy of morals. Cambridge University Press. (Original work published 1885)

Salmela, M. (2019). Shame and its political consequences in the age of neoliberalism. In C. Mun (Ed.), Interdisciplinary perspectives on shame: Methods, theories, norms, cultures, and politics (pp. 177-198). Lexington Books.

Salmela, M., \& Capelos, T. (2021). Ressentiment: A com- plex emotion or an emotional mechanism of psychic defences? Politics and Governance, 9(3), 191-203.

Salmela, M., \& von Scheve, C. (2018). Emotional dynamics of right- and left-wing political populism. Humanity \& Society, 42(4), 434-454.

Salmela, M., \& von Scheve, C. (2017). Emotional roots of right-wing political populism. Social Science Information, 56(4), 567-595.

Scheler, M. (1961). Ressentiment. Marquette University Press. (Original work published 1915)

Sullivan, G. B. (2021). Political reactionism as affective practice: UKIP supporters and non-voters in pre-Brexit England. Politics and Governance, 9(3), 260-273.

Wolfe, A. B. (1923). Conservatism, radicalism, and scientific method: An essay on social attitudes. The MacMillan Company.

\section{About the Authors}
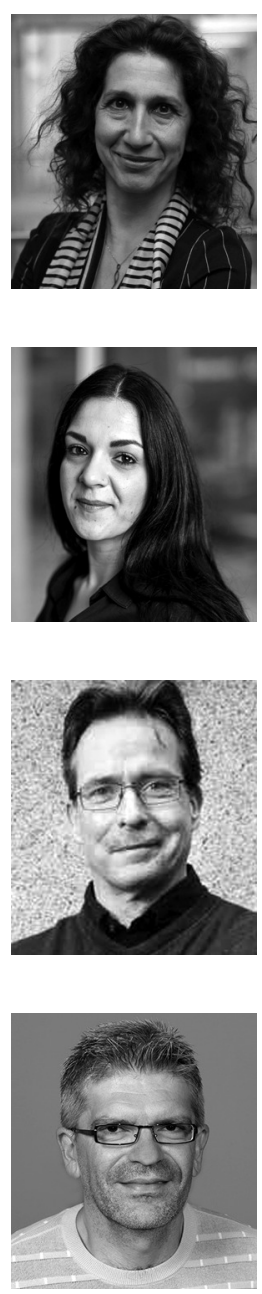

Tereza Capelos is Associate Professor in Political Psychology and Director of the Institute for Conflict Cooperation and Security (ICCS) at the University of Birmingham. She is President of the International Society of Political Psychology, Standing Group Co-Convener for the ECPR Political Psychology Standing Group and Co-Editor of the Palgrave Series in Political Psychology. Her research examines reactionary orientations and ressentimentful affect as psychological expressions of grievance politics, and the role of uncertainty and affective ambivalence in establishing trust during international crises and tensions.

Stavroula Chrona is a Teaching Fellow in European and International Studies at the Department of European and International Studies at King's College London. She is the Programme Co-Chair of the 2022 ISPP Annual Meeting, a Member of the Steering Committee of the ECPR Political Psychology Standing Group and the ECPR Southern European Politics Standing Group. Her research explores the affective, cognitive, and motivational processes that drive participatory behaviour in times of crisis focusing in particular on the role of affect, ideological inclinations, political sophistication, and values.

Mikko Salmela is an Adjunct Professor of Practical Philosophy and a Member of the Helsinki Hub on Emotions, Populism, and Polarisation (HEPP) at the University of Helsinki, and an Associate Professor at the Center for Subjectivity Research, University of Copenhagen. His main research interests are in empirically informed philosophy of emotion, philosophical and political psychology, and philosophy of sociality.

Cristiano Bee is a Senior Lecturer in Politics at Oxford Brookes University (UK), where he holds the Jean Monnet Module "Challenges to European Integration: Multidisciplinary Perspectives." His research focuses on civil society studies, social movements, political participation, and civic engagement with a particular interest on the role played by active citizens at the EU level but also comparatively in a number of countries (such as the UK, Italy, and Turkey). He is author of Active Citizenship in Europe: Practices and Demands in the EU, Italy, Turkey and the UK published by Palgrave in 2017. 